\title{
Case Report \\ Co-Infection of COVID-19 and Pneumocystosis Following Rituximab Infusion-A Case Report
}

\author{
Michelle Dakowitz, Justyna Korus (D, Oktawia Mazanowska, Magdalena Krajewska (D) and Dorota Kamińska *(D)
}

Department of Nephrology and Transplantation Medicine, Wroclaw Medical University, Borowska 213, 50-367 Wroclaw, Poland; michelle.dakowitz@dakowitz.de (M.D.); justyna.korus@student.umw.edu.pl (J.K.); oktawia.mazanowska@umw.edu.pl (O.M.); magdalena.krajewska@umw.edu.pl (M.K.)

* Correspondence: dorota.kaminska@umw.edu.pl; Tel.: +48-71-7332500; Fax: +48-71-7332509

\begin{abstract}
Immunocompromised patients with respiratory viral infections are at increased risk of fungal superinfections, including Pneumocystosis. Within the scope of the COVID-19 pandemic, Pneumocystis jirovecii co-infections are being increasingly reported. Differential diagnosis often creates a dilemma, due to multiple overlapping clinical and radiographic features. Awareness of fungal co-infections in the context of the COVID-19 pandemic is crucial to initiate prophylactic measures, especially in high-risk individuals. We report the second case of Pneumocystis jirovecii pneumonia and COVID-19 co-infection in a renal transplant recipient in Poland.
\end{abstract}

Keywords: COVID-19; kidney transplantation; Pneumocystis

check for

updates

Citation: Dakowitz, M.; Korus, J.; Mazanowska, O.; Krajewska, M.; Kamińska, D. Co-Infection of COVID-19 and Pneumocystosis Following Rituximab Infusion-A Case Report. Transplantology 2022, 3 83-90. https://doi.org/10.3390/ transplantology3010008

Academic Editor: Pasquale Esposito

Received: 31 December 2021

Accepted: 21 February 2022

Published: 24 February 2022

Publisher's Note: MDPI stays neutral with regard to jurisdictional claims in published maps and institutional affiliations.

Copyright: (c) 2022 by the authors. Licensee MDPI, Basel, Switzerland. This article is an open access article distributed under the terms and conditions of the Creative Commons Attribution (CC BY) license (https:// creativecommons.org/licenses/by/ $4.0 /)$.

\section{Introduction}

Immunocompromised patients frequently develop infection caused by the pathogen Pneumocystis jirovecii (PJP), leading to the development of pneumonia, which can be lifethreatening [1]. Patients who have cancer, acquired immune deficiency syndrome (AIDS), or who are transplant recipients are particularly vulnerable to PJP infection. Symptoms of pneumonia include fever, shortness of breath or cough, and in severe cases respiratory failure [2]. However, it should be noted that currently the majority of PJP patients are not infected with human immunodeficiency virus (HIV) [3].

COVID-19 caused by the severe acute respiratory syndrome coronavirus 2 (SARS$\mathrm{CoV}-2)$ is a disease that specifically attacks the respiratory system. It spreads through droplet particles excreted by the patient during coughing or sneezing [4]. In the era of the COVID-19 pandemic, the diagnosis of pneumonia caused by PJP creates a challenge due to the fact that both diseases show common clinical symptoms and a similar computed tomography (CT) scan image [5]. We report a case of a renal transplant recipient, who developed PJP with concomitant COVID-19 infection. Despite characteristic CT findings for COVID-19, PCR test results for COVID-19 were repeatedly negative/inconclusive.

\section{Case Report}

A 48-year-old male who underwent kidney transplantation (30 November 2013) due to primary focal segmental glomerulosclerosis (FSGS) was admitted in February 2021 to the Department of Nephrology and Transplantation Medicine of the University Clinical Hospital in Wrocław, Poland, because of elevated CRP levels $(250.4 \mathrm{mg} / \mathrm{L})$ found in the Transplant Outpatient Clinic. He presented in moderately severe condition, with fever $\left(38-39^{\circ} \mathrm{C}\right)$, cough, dyspnoea and myalgia. The symptoms had started several days before. He denied anosmia and ageusia.

Four months prior, an allograft biopsy was performed (21 September 2020), due to the deterioration of filtration function of the transplanted kidney with an increase in serum creatinine concentration $(1.58 \mathrm{mg} / \mathrm{dL}$; reference range $<1.0 \mathrm{mg} / \mathrm{dL})$ proteinuria $(1.0 \mathrm{~g} / \mathrm{L}$; reference range $<0.3 \mathrm{~g} / \mathrm{L})$ and haematuria. The biopsy revealed a lymphocytic 
infiltration located predominantly on the fibrotic interstitial area (total inflammation ti $8-10 \%$ of the cortical part of the biopsy, IF/TA grade I). In addition, the morphological image of the glomeruli corresponded to focal segmental glomerulosclerosis (FSGS), not otherwise specified. Afterwards, it was decided to increase dosages of prednisone (to $20 \mathrm{mg}$ for one month), mycophenolate mofetil to $1 \mathrm{~g}$ twice daily (previous dose was $0.5 \mathrm{~g}$ twice daily), and tacrolimus to reach levels between 7 and $8 \mathrm{ng} / \mathrm{mL}$. Prior in 2007, the patient developed end-stage renal failure in the course of FSGS and was subsequently qualified for renal transplantation surgery. Due to pathological and clinical signs of FSGS recurrence in the graft, antiCD-20 therapy was planned. During the next hospitalization, an abdominal ultrasound was performed, which showed an increased echogenicity of the parenchymal layer and a hypoechoic rim along the dorsum of the transplanted kidney, indicating oedema.

In the beginning of December 2020, the patient received an infusion of Rituximab (Mabtera) $500 \mathrm{mg}$, which was well tolerated and effective. After the infusion, a decrease in the number of total lymphocytes (from $3.46 \times 10^{3} / \mu \mathrm{L}$ to $0.47 \times 10^{3} / \mu \mathrm{L}$ ), and an improvement in blood pressure control was observed. Laboratory tests carried out after the infusion presented T lymphocytes - 688 cells $/ \mu \mathrm{L}$, and a severe B lymphocytes depletion0 cells $/ \mu \mathrm{L}$. In comparison, previous measurements in October 2020 showed B lymphocytes at 569 cells $/ \mu \mathrm{L}$ and T lymphocyte levels at 2377 cells $/ \mu \mathrm{L}$. On re-admission to the Clinic in February, the heart rate of the patient was $96 / \mathrm{min}$, blood pressure $140 / 90 \mathrm{mmHg}$ and $\mathrm{O}_{2}$ saturation $70-75 \%$ without administered oxygen (increased to $98 \%$ after oxygen administration). Laboratory studies showed: d-dimer $0.8 \mu \mathrm{g} / \mathrm{mL}, \mathrm{CRP} 250 \mathrm{mg} / \mathrm{L}$, NT-proBNP $2141.3 \mathrm{pg} / \mathrm{mL}$ and LDH $759 \mathrm{U} / \mathrm{L}$. An oropharyngeal swab for SARS-CoV-2 polymerase chain reaction (PCR) was negative. Repeated testing on the following day also gave a negative result. In the chest X-ray, hilar thickening was visible-suggesting inflammatory changes that were not visible on a comparison image from November 2020. A CT scan of the chest showed bilateral areas of opaque ground-glass opacifications with cobblestone pattern and small consolidations located subpleurally in the lower lung lobes-consistent with changes in the course of viral inflammation.

Respiratory support using AirVo (80\%, 60 L) was initiated. Two days later SpO2 sunk to $80 \%$, which resulted in the decision to intubate the patient. Quantitative PCR test for Pneumocystis jirovecii gave a positive result, while PCR for SARS-CoV-2 was inconclusive. Meanwhile, several infectious investigations for viruses, bacteria and fungi were performed. A multitest for respiratory pathogens including Influenza virus (A, B), RSV, Parainfluenza virus, Rhinovirus, Enterovirus, Legionella pneumophila, Haemophilus influenza, Streptococcus pneumoniae and Moraxella catarrhalis as well as Chlamydophila pneumoniae and Mycoplasma pneumoniae was negative. Tuberculosis infection was excluded by a QuantiFERON test. Fungal antigen tests for Aspergillus sp., Candida sp. and Legionella also revealed negative results.

Despite strict adherence to hospital mitigation strategies, our patient transmitted COVID-19 to several fellow patients in the nephrological department. The patient was transferred to the intensive care unit, where mechanical ventilation and pharmacological treatment including analgosedation (propofol, fentanyl), and immunosuppressive treatment (tacrolimus, methylprednisolone) continued. Additionally, Piperacillin-tazobactam and Co-trimoxazole were introduced. On neurological examination pupils were even, narrow, and reactive. An ultrasound examination of the lungs revealed numerous B-lines and subpleural consolidation, predominantly on the right side. A few days later renal replacement therapy was started, due to worsening metabolic acidosis and rising creatinine $(2.71 \mathrm{mg} / \mathrm{dL})$ and urea levels $(131 \mathrm{mg} / \mathrm{dL})$.

On the 20 February 2021, cardiovascular performance improved, thus catecholamine administration was stopped. Pharmacological treatment was continued with the addition of empirical broad-spectrum antibiotics. These included meropenem, levofloxacin, vancomycin and colistin. Antibiotic therapy was later modified according to the results of microbiological cultures. Two days later, the patient developed extreme respiratory insuffi- 
ciency and hypoxemia, despite ventilation with 100\% oxygen. In ultrasound examination: no signs of lung emphysema, but multiple subpleural and interstitial consolidations and features of pulmonary oedema in the lower parts of the lung.

Despite recruitment manoeuvres and ventilation in the prone position, the state of the patient deteriorated with severe respiratory acidosis (pCO2-92 $\mathrm{mmHg}$ and $\mathrm{pH}-6.963$ ), increase in d-dimer to $1.2 \mu \mathrm{g} / \mathrm{mL}$ and procalcitonin to $1.3 \mathrm{ng} / \mathrm{mL}$ in laboratory studies and refractory hypotension (BP 70/40 $\mathrm{mmHg}$ ), in spite of vasopressor infusion and renal replacement therapy. On the 2 March, he died from multiple organ dysfunction syndrome and respiratory failure. No autopsy was performed.

\section{Discussion}

Coronavirus disease (COVID-19), caused by the severe acute respiratory distress syndrome coronavirus 2 (SARS-CoV-19) has led to a global pandemic that resulted in approximately 224,511,226 confirmed cases, including 4,627,540 deaths, posing a significant burden to the health care system (World Health Organisation report as of 13 September 2021). Approximately, $5 \%$ of ambulatory patients and $20 \%$ of hospitalized patients require intensive care treatment, of which $40 \%$ result in fatal outcome [6,7]. Fungal co-infections are known to significantly increase mortality [8].

Immunocompromised patients, such as patients after solid-organ transplantation, who developed COVID-19, have a higher probability to develop fungal superinfections, in comparison to immunocompetent individuals [9].

Apart from Aspergillosis [10], opportunistic mycoses such as Pneumocystosis have been increasingly described in COVID-19 patients, especially in those suffering HIV [11-13]. The remaining cases of co-infection have been reported in patients with malignancies $[14,15]$ and kidney-transplant recipients [16,17].

To the best of our knowledge, we report the third case of COVID-19 and PJP coinfection in a renal-transplant recipient in Europe.

One case was in a 47-year-old man in Poland [16], who was taking cyclosporine for immunosuppressive treatment, and developed acute kidney injury caused by an interaction between cyclosporine and clarithromycin. The degree of immunosuppression is unclear, as exact lymphocyte counts are not disclosed.

The other case of co-infection with COVID-19 and PJP in a kidney transplant recipient was in a 65-year-old male in Italy [17], whose baseline immunosuppressive regimen consisted of tacrolimus, mycophenolate mofetil and methylprednisolone.

This patient showed a persistence in low lymphocyte counts with CD4+ cells at 35 cells $/ \mathrm{mL}$ and an inversed ratio of CD4+/CD8+, while our patient had CD3+ cells at 654 cells $/ \mathrm{mL}$ and CD19+ values at 0 cells / $\mathrm{mL}$ as a consequence of the Rituximab infusion, that was implicated due to the risk of transplant rejection. In addition, our patient was also taking prednisone orally over the course of several months. Both patient cases resulted in fatal outcome, which may be attributable to the extent of immunosuppression.

Both, underlying disease and treatment in immunocompromised patients with respiratory viral infection result in impaired immune responses that predispose patients to opportunistic mycoses $[7,9,18]$. Treatment with immunosuppressive agents, including calcineurin inhibitors (CNI), anti-rejection therapy and prolonged treatment with systemic steroids are significant risk factors for PJP development [19].

Interestingly, one case reports co-infection in a 83-year old female patient without known underlying immunodeficiency, who presented with CD4+ count at 291 cells / $\mu \mathrm{L}$ [20]. In severe COVID-19 cases, absolute numbers of T lymphocytes, CD4+ T cells and CD8+ $\mathrm{T}$ cells can be remarkably low [21]. According to Menon [20], an infection with SARSCoV-2 may cause CD4 lymphocyte depletion and suppressed functional immunity, which may predispose to Pneumocystis activation and proliferation. An observational study by Alanio et al. reported that $P$. jirovecii PCR was positive in 10 out of 108 (9.3\%) patients with severe SARS-CoV-2 infection [22]. Of note, this group presented a higher frequency of long-term corticosteroid prescriptions. 
However, more than half of these patients had low serum Beta-D-glucan levels and did not receive treatment for PJP and finally presented with similar mortality as patients in the treated group, suggesting possible PJP colonization rather than co-infection [23].

On the contrary, a study by Blaize et al. declared no linkage between COVID-19 induced lymphocytopenia and PJP infection, by finding that only two among 145 patients $(1.4 \%)$ with severe COVID-19 had a positive polymerase chain reaction (PCR) for Pneumocystis jirovecii [24].

In light of the current data, it is not possible to accurately determine the true incidence, risk factors and prognosis of COVID-19 patients with PJP coinfections. Immunosuppressive therapies and untreated HIV infection with low CD4+ cell count are presumably predisposing factors for PJP coinfection [23].

Although cases of COVID-19 and concurrent Pneumocystis infection have been reported, ref. [11-17,22] fungal co-infection in COVID-19 patients seem to be underestimated in a clinical setting [22]. The diagnosis and differentiation of COVID and PJP poses a diagnostic challenge, because of numerous overlapping clinical and radiologic features [11,25,26]. Clinically, COVID-19 and PJP present with fever, fatigue, dry cough, tachypnoea, dyspnoea, desaturation, and relatively normal chest auscultation $[11,25,26]$. PJP is generally characterized by a more subacute course than COVID-19, with symptoms commonly occurring weeks before diagnosis [23]. Dyspnoea is also a more frequent sign in PJP and can be seen in up to $95 \%$ of patients, whereas it is only observed in about $11 \%$ to $31 \%$ of COVID-19 patients [27-30].

Multifocal ground-glass opacities with interlobular septal thickening are the key radiographic finding in COVID-19 and PJP, complicating differential diagnosis [11,31]. However, COVID-19-related ground glass changes frequently present with multi-lobar distribution, with a predilection for the lung peripheries [32]. In contrast, increasingly recognized characteristic radiologic findings of PJP include bilateral parenchymal opacities, most prominent in the upper lobes, with sparing of the lung bases $[33,34]$. Additionally, pulmonary cysts may occur in one third of patients with PJP [33-35].

The laboratory diagnosis of Pneumocystis pneumonia can be made by real-time quantitative (RTqPCR) assays from respiratory specimens, mainly of bronchoalveolar lavage fluids (BAL) and throat swabs [36]. SARS-CoV-2 RNA detection is made by RT-PCR from throat swabs, tracheal aspirates or bronchoalveolar lavage samples [37]. The sensitivity of RT-PCR depends on the type of specimen [38] and on the timing, as sensitivity drops from $100 \%$ to $40 \%$ after day 5 of symptom onset [39]. A limitation of our study is that we cannot define this case as proven COVID-19, as we were unable to detect SARS-CoV-2 by PCR in respiratory tract specimen. It is inconclusive why in our patient the SARS-CoV-2 PCR testing results remained negative, however epidemiological data as well as clinical and radiological symptoms strongly supported the diagnosis of COVID-19.

The ideal treatment strategy for PJP and COVID-19 co-infection in transplant recipients remains unsettled. The British Transplantation Society (BTS) and UK Kidney Association (UKKA) released guidance for the management of transplanted patients with COVID-19 (Figure 1). General principles suggest discontinuation of antiproliferative agents (such as azathioprine and mycophenolate mofetil), minimization of calcineurin inhibitors in early disease stages and reduction/discontinuation in progressive stages [40]. 


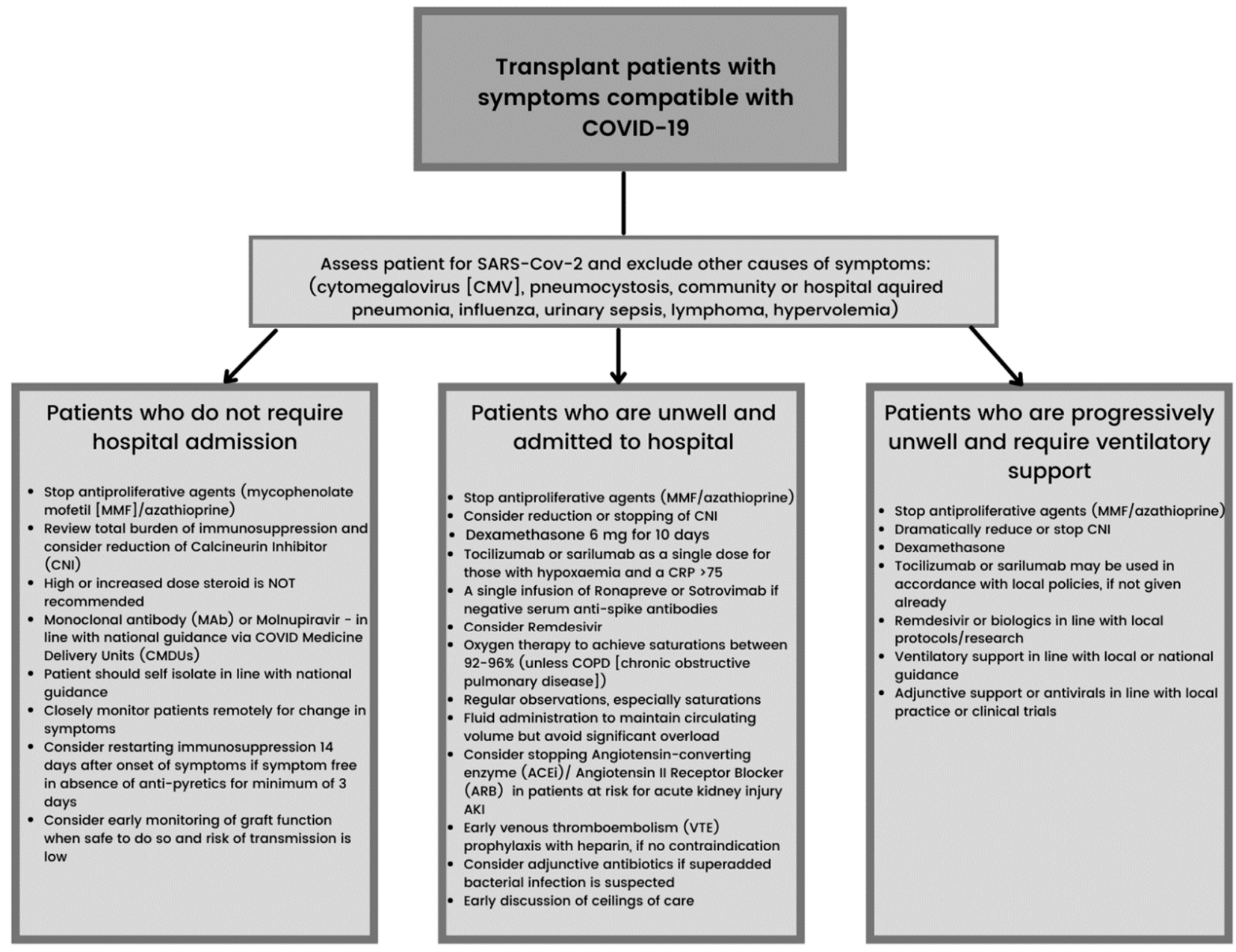

Figure 1. BTS (British Transplantation Society) and UKKA (United Kingdom Kidney Association) guidance on the management of transplant recipients diagnosed with or suspected of having COVID19 (updated 27 January 2022).

According to Baker et al., all renal transplant recipients with confirmation of Pneumocystis jirovecii in respiratory secretions should be treated for 14-21 days with co-trimoxazole orally or intravenously (15-20 mg/ kg in three or four divided doses). Second-line treatment is pentamidine. Adjunctive glucocorticoid therapy may be considered in advanced disease [41].

Management of co-infection with PJP and COVID-19 can be complicated by the controversy of high-dose corticosteroid therapy, which is recommended in severe PJP [42], but not for early COVID-19 treatment [43]. Choudhari et al. suggest co-trimoxazole as adjuvant therapy in critically ill COVID-19 patients, due to its anti-inflammatory and immunomodulatory action [44]. Co-trimoxazole has proven efficacy in PJP prophylaxis in immunocompromised patients $[45,46]$, hence it could be of value in critically ill COVID-19 patients.

\section{Conclusions}

In the scope of the COVID-19 pandemic, physicians have directed their focus to diagnosing COVID-19 in patients with respiratory symptoms, consequently creating a risk of neglecting differential diagnoses, including Pneumocystis jirovecii pneumonia. Moreover, numerous overlapping clinical and radiographic features of COVID-19 and PJP can pose a diagnostic challenge. We report a case of a kidney transplant recipient who developed co-infection of PJP and COVID-19, which resulted in fatal outcome. With diagnostic and treatment delay directly affecting mortality, the awareness of co-infections in the current COVID-19 pandemic is crucial in reducing morbidity and mortality. Because of a lack of 
evidence-based research, there are no guidelines for the treatment of COVID-19 in transplant patients and scientific evidence about co-infection of COVID-19 and PJP in transplant recipients is scarce. Along with previous case reports of COVID-19 and concurrent PJP infection, we recommend Beta-D-glucan testing and underline the importance of systematic investigations for Pneumocystis jirovecii in deep respiratory specimens, especially in immunocompromised patients.

Author Contributions: Conceptualization, M.D., J.K. and D.K.; writing—original draft preparation, M.D.; writing review and editing, M.D. and J.K.; review, editing and supervision, O.M., M.K. and D.K. All authors have read and agreed to the published version of the manuscript.

Funding: This research received no external funding.

Institutional Review Board Statement: Not applicable.

Informed Consent Statement: Not applicable.

Data Availability Statement: Not applicable.

Conflicts of Interest: The authors declare no conflict of interest.

\section{References}

1. Gingerich, A.D.; Norris, K.A.; Mousa, J.J. Pneumocystis Pneumonia: Immunity, Vaccines, and Treatments. Pathogens 2021, 10, 236. [CrossRef]

2. Catherinot, E.; Lanternier, F.; Bougnoux, M.E.; Lecuit, M.; Couderc, L.J.; Lortholary, O. Pneumocystis jirovecii Pneumonia. Infect. Dis. Clin. N. Am. 2010, 24, 107-138. [CrossRef] [PubMed]

3. Grønseth, S.; Rogne, T.; Hannula, R.; Åsvold, B.O.; Afset, J.E.; Damås, J.K. Semiquantitative Real-Time PCR to Distinguish Pneumocystis Pneumonia from Colonization in a Heterogeneous Population of HIV-Negative Immunocompromised Patients. Microbiol. Spectr. 2021, 9, e00026-21. [CrossRef] [PubMed]

4. Islam, K.U.; Iqbal, J. An Update on Molecular Diagnostics for COVID-19. Front. Cell. Infect. Microbiol. 2020, 10, 694. [CrossRef] [PubMed]

5. Goyal, N.; Chung, M.; Bernheim, A.; Keir, G.; Mei, X.; Huang, M.; Li, S.; Kanne, J.P. Computed Tomography Features of Coronavirus Disease 2019 (COVID-19). J. Thorac. Imaging 2020, 35, 211-218. [CrossRef] [PubMed]

6. Wiersinga, W.J.; Rhodes, A.; Cheng, A.C.; Peacock, S.J.; Prescott, H.C. Pathophysiology, Transmission, Diagnosis, and Treatment of Coronavirus Disease 2019 (COVID-19). JAMA 2020, 324, 782. [CrossRef]

7. Jeican, I.I.; Inișca, P.; Gheban, D.; Tăbăran, F.; Aluaș, M.; Trombitas, V.; Cristea, V.; Crivii, C.; Junie, L.M.; Albu, S. COVID-19 and Pneumocystis jirovecii Pulmonary Coinfection-The First Case Confirmed through Autopsy. Medicina 2021, 57, 302. [CrossRef]

8. Peng, J.; Wang, Q.; Mei, H.; Zheng, H.; Liang, G.; She, X.; Liu, W. Fungal co-infection in COVID-19 patients: Evidence from a systematic review and meta-analysis. Aging 2021, 13, 7745-7757. [CrossRef]

9. Manuel, O.; Estabrook, M. RNA respiratory viral infections in solid organ transplant recipients: Guidelines from the American Society of Transplantation Infectious Diseases Community of Practice. Clin. Transplant. 2019, 33, e13511. [CrossRef]

10. Rutsaert, L.; Steinfort, N.; Van Hunsel, T.; Bomans, P.; Naesens, R.; Mertes, H.; Dits, H.; Van Regenmortel, N. COVID-19-associated invasive pulmonary aspergillosis. Ann. Intensive Care 2020, 10, 71. [CrossRef]

11. Coleman, H.; Snell, L.B.; Simons, R.; Douthwaite, S.T.; Lee, M.J. Coronavirus disease 2019 and Pneumocystis jirovecii pneumonia: A diagnostic dilemma in HIV. AIDS 2020, 34, 1258-1260. [CrossRef] [PubMed]

12. Bhat, P.; Noval, M.; Doub, J.B.; Heil, E. Concurrent COVID-19 and Pneumocystis jirovecii pneumonia in a severely immunocompromised 25-year-old patient. Int. J. Infect. Dis. 2020, 99, 119-121. [CrossRef]

13. Rubiano, C.; Tompkins, K.; Sellers, S.A.; Bramson, B.; Eron, J.; Parr, J.B.; Schranz, A.J. Pneumocystis and Severe Acute Respiratory Syndrome Coronavirus 2 Coinfection: A Case Report and Review of an Emerging Diagnostic Dilemma. Open Forum Infect. Dis. 2021, 8, ofaa633. [CrossRef] [PubMed]

14. Mouren, D.; Goyard, C.; Catherinot, E.; Givel, C.; Chabrol, A.; Tcherakian, C.; Longchampt, E.; Vargaftig, J.; Farfour, E.; Legal, A.; et al. COVID-19 and Pneumocystis jirovecii pneumonia: Back to the basics. Respir. Med. Res. 2021, 79, 100814. [CrossRef] [PubMed]

15. Gerber, V.; Ruch, Y.; Chamaraux-Tran, T.N.; Oulehri, W.; Schneider, F.; Lindner, V.; Greigert, V.; Denis, J.; Brunet, J.; Danion, F. Detection of Pneumocystis jirovecii in Patients with Severe COVID-19: Diagnostic and Therapeutic Challenges. J. Fungi $2021,7,585$. [CrossRef] [PubMed]

16. Skonieczny, P.; Heleniak, Z.; Szostakiewicz, M.; Kuziemski, K.; Dębska-Ślizień, A. Co-infection of COVID-19 and pneumocystosis in the patient after kidney transplantation. Pol. Arch. Intern. Med. 2021, 131, 566-567. [CrossRef]

17. De Francesco, M.A.; Alberici, F.; Bossini, N.; Scolari, F.; Pascucci, F.; Tomasoni, G.; Caruso, A. Pneumocystis jirevocii and SARS-CoV-2 Co-Infection: A Common Feature in Transplant Recipients? Vaccines 2020, 8, 544. [CrossRef]

18. Waghmare, A.; Englund, J.A.; Boeckh, M. How I treat respiratory viral infections in the setting of intensive chemotherapy or hematopoietic cell transplantation. Blood 2016, 127, 2682-2692. [CrossRef] 
19. Sokulska, M.; Kicia, M.; Wesołowska, M.; Hendrich, A.B. Pneumocystis jirovecii-From a commensal to pathogen: Clinical and diagnostic review. Parasitol. Res. 2015, 114, 3577-3585. [CrossRef]

20. Menon, A.A.; Berg, D.D.; Brea, E.J.; Deutsch, A.J.; Kidia, K.K.; Thurber, E.G.; Polsky, S.B.; Yeh, T.; Duskin, J.A.; Holliday, A.M.; et al. A Case of COVID-19 and Pneumocystis jirovecii Coinfection. Am. J. Respir. Crit. Care Med. 2020, 202, 136-138. [CrossRef]

21. Gangneux, J.P.; Bougnoux, M.E.; Dannaoui, E.; Cornet, M.; Zahar, J.R. Invasive fungal diseases during COVID-19: We should be prepared. J. Mycol. Méd. 2020, 30, 100971. [CrossRef] [PubMed]

22. Alanio, A.; Dellière, S.; Voicu, S.; Bretagne, S.; Mégarbane, B. The presence of Pneumocystis jirovecii in critically ill patients with COVID-19. J. Infect. 2021, 82, 84-123. [CrossRef] [PubMed]

23. Chong, W.H.; Saha, B.K.; Chopra, A. Narrative review of the relationship between COVID-19 and PJP: Does it represent coinfection or colonization? Infection 2021, 49, 1079-1090. [CrossRef] [PubMed]

24. Blaize, M.; Mayaux, J.; Luyt, C.E.; Lampros, A.; Fekkar, A. COVID-19-related Respiratory Failure and Lymphopenia Do Not Seem Associated with Pneumocystosis. Am. J. Respir. Crit. Care Med. 2020, 202, 1734-1736. [CrossRef]

25. Choy, C.Y.; Wong, C.S. It's not all about COVID-19: Pneumocystis pneumonia in the era of a respiratory outbreak. J. Int. AIDS Soc. 2020, 23, e25533. [CrossRef] [PubMed]

26. Hughes, W.T. Medical Microbiology, 4th ed.; University of Texas Medical Branch at Galveston: Galveston, TX, USA, 1996; Chapter 85; ISBN 10:0-9631172-1-1.

27. Wang, D.; Hu, B.; Hu, C.; Zhu, F.; Liu, X.; Zhang, J.; Wang, B.; Xiang, H.; Cheng, Z.; Xiong, Y.; et al. Clinical Characteristics of 138 Hospitalized Patients with 2019 Novel Coronavirus-Infected Pneumonia in Wuhan, China. JAMA 2020, 323, 1061. [CrossRef] [PubMed]

28. Kales, C.P. Early Predictors of In-Hospital Mortality for Pneumocystis carinii Pneumonia in the Acquired Immunodeficiency Syndrome. Arch. Intern. Med. 1987, 147, 1413. [CrossRef]

29. Chen, N.; Zhou, M.; Dong, X.; Qu, J.; Gong, F.; Han, Y.; Qiu, Y.; Wang, J.; Liu, Y.; Wei, Y.; et al. Epidemiological and clinical characteristics of 99 cases of 2019 novel coronavirus pneumonia in Wuhan, China: A descriptive study. Lancet 2020, 395, 507-513. [CrossRef]

30. Young, B.E.; Ong, S.W.X.; Kalimuddin, S.; Low, J.G.; Tan, S.Y.; Loh, J.; Ng, O.T.; Marimuthu, K.; Ang, L.W.; Mak, T.M.; et al. Epidemiologic Features and Clinical Course of Patients Infected with SARS-CoV-2 in Singapore. JAMA 2020, 323, 1488. [CrossRef]

31. Fung, M.; Babik, J.M. COVID-19 in Immunocompromised Hosts: What We Know So Far. Clin. Infect. Dis. 2021, 72, 340-350. [CrossRef]

32. Salehi, S.; Abedi, A.; Balakrishnan, S.; Gholamrezanezhad, A. Coronavirus Disease 2019 (COVID-19): A Systematic Review of Imaging Findings in 919 Patients. Am. J. Roentgenol. 2020, 215, 87-93. [CrossRef] [PubMed]

33. Fujii, T.; Iwamoto, A.; Nakamura, T.; Iwamoto, A.; Iwamoto, A.; Iwamoto, A. Pneumocystis pneumonia in patients with HIV infection: Clinical manifestations, laboratory findings, and radiological features. J. Infect. Chemother. 2007, 13, 1-7. [CrossRef] [PubMed]

34. Boiselle, P.M.; Crans, C.A.; Kaplan, M.A. The changing face of Pneumocystis carinii pneumonia in AIDS patients. Am. J. Roentgenol. 1999, 172, 1301-1309. [CrossRef] [PubMed]

35. Kuhlman, J.E.; Kavuru, M.; Fishman, E.K.; Siegelman, S.S. Pneumocystis carinii pneumonia: Spectrum of parenchymal CT findings. Radiology 1990, 175, 711-714. [CrossRef] [PubMed]

36. Mercier, T.; Aissaoui, N.; Gits-Muselli, M.; Hamane, S.; Prattes, J.; Kessler, H.H.; Mareković, I.; Pleško, S.; Steinmann, J.; Scharmann, U.; et al. Variable Correlation between Bronchoalveolar Lavage Fluid Fungal Load and Serum- $(1,3)-\beta$-d-Glucan in Patients with Pneumocystosis-A Multicenter ECMM Excellence Center Study. J. Fungi 2020, 6, 327. [CrossRef]

37. Pascarella, G.; Strumia, A.; Piliego, C.; Bruno, F.; Del Buono, R.; Costa, F.; Scarlata, S.; Agrò, F. COVID-19 diagnosis and management: A comprehensive review. J. Intern. Med. 2020, 288, 192-206. [CrossRef]

38. Nairz, M.; Bellmann-Weiler, R.; Ladstätter, M.; Schüllner, F.; Zimmermann, M.; Koller, A.M.; Blunder, S.; Naschberger, H.; Klotz, W.; Herold, M.; et al. Overcoming limitations in the availability of swabs systems used for SARS-CoV-2 laboratory diagnostics. Sci. Rep. 2021, 11, 2261. [CrossRef]

39. Wölfel, R.; Corman, V.M.; Guggemos, W.; Seilmaier, M.; Zange, S.; Müller, M.A.; Niemeyer, D.; Jones, T.C.; Vollmar, P.; Rothe, C.; et al. Virological assessment of hospitalized patients with COVID-2019. Nature 2020, 581, 465-469. [CrossRef]

40. British Transplantation Society; UK Kidney Association. Guidance on the Management of Transplant Recipients Diagnosed with or Suspected of Having COVID19. Available online: https:/ /bts.org.uk/wp-content/uploads/2022/01/Clinical-managementof-transplants-and-immunosuppression-28th-Januray-2022-003.pdf (accessed on 14 February 2022).

41. Baker, R.J.; Mark, P.B.; Patel, R.K.; Stevens, K.K.; Palmer, N. Renal association clinical practice guideline in post-operative care in the kidney transplant recipient. BMC Nephrol. 2017, 18, 174. [CrossRef]

42. Nelson, M.; Dockrell, D.; Edwards, S. British HIV Association and British Infection Association guidelines for the treatment of opportunistic infection in HIV-seropositive individuals 2011. HIV Med. 2011, 12, 1-5. [CrossRef]

43. Russell, C.D.; Millar, J.E.; Baillie, J.K. Clinical evidence does not support corticosteroid treatment for 2019-nCoV lung injury. Lancet 2020, 395, 473-475. [CrossRef]

44. Choudhari, O.K.; Spalgis, S.; Ojha, U.C. Cotrimoxazole as adjuvant therapy in critical ill COVID 19 patients. J. Ideas Health 2020, 3 (Suppl. S1), 196-197. [CrossRef] 
45. Kovacs, J.A. New Insights into Transmission, Diagnosis, and Drug Treatment of Pneumocystis carinii Pneumonia. JAMA 2001, 286, 2450. [CrossRef] [PubMed]

46. Centers for Disease Control (CDC). Guidelines for prophylaxis against Pneumocystis carinii pneumonia for persons infected with human immunodeficiency virus. MMWR Suppl. 1989, 38, 1-9. 